\title{
Construções comparativas em Karitiana: descrição preliminar
}

\author{
Comparative constructions in Karitiana: a preliminary description
}

Luciana Sanchez Mendes

Universidade Federal Fluminense

RESUMO: Este trabalho tem como objetivo apresentar uma descrição preliminar das construções comparativas em Karitiana (uma língua nativa da América do Sul falada em Rondônia, Brasil, família Arikén, tronco Tupi). Primeiramente, o artigo investiga essas construções considerando o Karitiana numa perspectiva tipológica. Desse ponto de vista, o Karitiana tem uma propriedade que é similar a outras línguas como o inglês e o português: ele expressa comparativas por uma palavra especializada para marcar o índice de comparação. Ohynym tem um papel semelhante ao do morfema comparativo \{er\} em inglês e o mais em português. No entanto, essa palavra significa 'maior' quando é usada sem um adjetivo modificado. Karitiana, no entanto, não tem uma marca para o padrão de comparação (como that do inglês e (do) que em português). Em seguida, o artigo considera duas hipóteses para a sintaxe de construções comparativas em Karitiana e defende que, em vez de serem biclausais, essas construções são expressas por uma sentença contendo um verbo auxiliar e um verbo principal.

Palavras-chave: Comparativas. Grau. Tupi. Tipologia

ABSTRACT: This paper aims to present a preliminary description of comparative constructions in Karitiana (a native language spoken in Rondônia, Brazil, Arikén branch, Tupi family). Firstly, the article investigates these constructions in order to consider Karitiana in a typological perspective. From this point of view, Karitiana has a property that is similar to other languages such as English and Portuguese: it expresses comparatives by a specialized word to mark the index of comparison. Ohynym has a similar role as the comparative morpheme $\{-e r\}$ in English and mais 'more' in Portuguese. However it means 'bigger' when it is used without a modified adjective. Karitiana doesn't have a mark to the contrast the standard of comparison (as than in English and (do) que in Portuguese). Secondly, the paper considers two hypotheses to the syntax of comparative constructions in Karitiana and defends that rather than being biclausal these constructions are expressed by one sentence containing an auxiliary and a main verb.

Keywords: Comparative. Degree. Tupian. Tipology.

\section{Introdução}

A capacidade de se fazer comparações entre objetos de acordo com o grau que cada um apresenta de uma determinada propriedade parece ser um componente básico da cognição humana (SAPIR, 1944; KENNEDY 2007). Segundo o trabalho clássico de Sapir, julgamentos de gradação são um processo psicológico preliminar necessário para julgamentos mais complexos como os de contagem e medida, mesmo que implicitamente (SAPIR, 
1944). Segundo o linguista americano, esse componente psicológico está envolvido em todos os processos de contagem e medida e é universal, mesmo que seja manifesto de formas diferentes nas línguas do mundo. Sua proposta prevê que mesmo falantes de línguas que não possuem expressões linguísticas que denotem medida exata sejam capazes de oferecer julgamentos que envolvem gradação.

Frank et al. (2008) exploraram essa hipótese com experimentos com falantes da língua Pirahã (Mura, Brasil)1, uma língua que não possui mecanismos linguísticos para expressar quantidade exata de nenhum tipo, nem mesmo o numeral um. Os experimentos que buscavam aferir as habilidades numéricas dos falantes de Pirahã mostraram que eles são capazes de realizar perfeitamente correspondências exatas com um grande número de objetos. Os resultados obtidos indicam que manifestações linguísticas de numerais e quantidades exatas são uma invenção cultural, e não um universal linguístico. O que seria universal é a capacidade cognitiva de identificar quantidades.

Uma vez que as construções gramaticais gradativas se utilizam do mesmo componente cognitivo da gradação utilizada para identificar quantidades, é possível assumir que as sentenças comparativas representam estruturas semânticas fundamentais que todas as línguas naturais devem possuir, ainda que de formas diferentes (ULTAN, 1972; KENNEDY, 2007; BOCHNAK, 2013).

Nessa perspectiva, o objetivo deste artigo é apresentar uma descrição preliminar das construções comparativas em Karitiana (Tupi) situando-as no panorama da variação translinguística. $O$ trabalho está dividido da seguinte forma: a seção 1 apresenta uma visão geral das construções comparativas; a seção 2 mostra um panorama translinguístico das construções comparativas a fim de apresentar a diversidade de formas empregadas pelas línguas para expressar comparação; a seção 3 apresenta o comportamento das sentenças comparativas no Karitiana abordando primeiramente suas características em uma perspectiva tipológica, e em seguida, apresentando uma análise morfossintática discutindo se essas construções apresentam uma ou duas orações; a seção 4 apresenta, por fim, as considerações finais.

\section{Construções Comparativas: visão geral}

De forma geral, as construções comparativas são definidas como as construções que têm a função de comparar dois indivíduos em relação a uma propriedade graduável (DIXON, 2008; STASSEN 1985, 2013, ULTAN, 1972)². Os ingredientes essenciais dos casos prototípicos dessas construções são: um predicado graduável e dois objetos (DIXON, 2008;

\footnotetext{
${ }^{1}$ Segundo a Convenção para Grafia dos Nomes Tribais da Associação Brasileira de Antropologia (ABA), a grafia de Pirahã deveria ser Pirahan (artigo 15). No entanto, mantemos a grafia Pirahã porque é a que foi consagrada pelo uso. Entretanto, seguiremos a convenção no que diz respeito à grafia dos nomes das línguas indígenas brasileiras com a primeira letra maiúscula.

${ }^{2} \mathrm{O}$ termo indivíduo é designado pelos autores também como objeto. Preferimos o termo indivíduo para evitar possíveis equívocos entre propriedade semântica e função sintática.
} 
STASSEN, 2013). Um exemplo de uma construção como essa em português é apresentado em (1):

O João é mais alto (do) que a Maria.

Dixon (2008) classifica cada uma das partes componentes de construções comparativas como (1) de acordo com sua função semântica. Os indivíduos dessas sentenças representam um termo COMPARADO (o João no exemplo acima) e um PADRÃO DE COMPARAÇÃo, objeto em relação ao qual o comparado está sendo relacionado (nesse caso, a Maria). A qualidade atribuída pelo predicado é definida como propriedade de comparação (alto nesse caso)3. Além disso, comparativas prototípicas geralmente, mas não obrigatoriamente, apresentam um índice de comparação. No caso do português, esse índice é o mais. O (do) que representa, segundo Dixon (2008), uma marca da função gramatical do padrão de comparação. É importante destacar que, do ponto de vista da distribuição translinguística, apenas o termo comparado, o padrão de comparação, e a propriedade de comparação são constituintes obrigatórios das construções comparativas.

A definição das construções comparativas apresentada foi elaborada por autores tipologistas e representa uma caracterização semântica. A vantagem de uma definição como essa é que ela abstrai dessas construções quaisquer idiossincrasias morfossintáticas que poderiam obscurecer a sua equivalência na comparação entre as línguas (BOCHNAK, 2013). Uma vez que esta pesquisa tem o objetivo de discutir os dados do Karitiana em um panorama translinguístico e tipológico, uma definição desse tipo é vantajosa.

A sentença apresentada no exemplo (1) representa um exemplo prototípico de sentença comparativa de superioridade. Há ainda as sentenças comparativas de inferioridade como (2a), equativas (ou comparativas de igualdade) (2b) e superlativas (2c).
a. A Maria é menos alta do que o João.
b. O Leandro é tão alto quanto o João.
c. O João é o mais alto dos jogadores.

Segundo Ultan (1972), as sentenças comparativas (de superioridade ou de inferioridade) e superlativas compartilham a noção de disparidade, ausente nas construções equativas. Construções comparativas e superlativas representam aspectos de um mesmo conceito. Por essa razão, em muitas línguas, há uma semelhança formal entre essas duas estruturas, em oposição às construções equativas. Em português, por exemplo, a construção superlativa é composta pela expressão comparativa (mais/menos) acrescida de um artigo definido. De uma amostra de 30 línguas analisadas, Ultan (1972) identificou que 18 apre-

\footnotetext{
${ }^{3} \mathrm{Na}$ literatura, a propriedade é chamada também de parameter. Decidiu-se manter propriedade para que não haja confusão com o padrão de comparação, do inglês standard of comparison que também pode ser traduzido por parâmetro de comparação por autores brasileiros.
} 
sentavam marcas idênticas para apresentar o padrão de comparação de comparativas e superlativas (como o mais do português). Por outro lado, apenas a língua tagalog (austronésia, Filipinas) apresenta a mesma forma para equativas e superlativas e nenhuma possui a mesma marca para construções comparativas e equativas.

Além dos casos prototípicos em que a comparação se dá entre dois indivíduos em relação a uma propriedade denotada por um predicado graduável, há ainda os casos em que um mesmo indivíduo é avaliado segundo duas propriedades como em (3a), os casos em que se comparam diferentes indivíduos possuindo diferentes propriedades (3b), ou ainda os que comparam o grau que um indivíduo possui de certa propriedade com grau de expectativa (3c).

(3) a. Mais meteoritos evaporam na atmosfera do que caem no solo.

b. A cratera era mais profunda do que a altura de um prédio de 50 andares.

c. O voo para Júpiter não foi tão longo quanto esperávamos.

(KENNEDY, 2007: 141, exemplos adaptados)

A maior parte dos exemplos dados até agora são de comparativas de base adjetival. Há ainda as sentenças comparativas com base adverbial (4a), nominal (4b) e verbal (4c).
a. João corre mais rápido que Pedro.
b. João comeu mais bananas que laranjas.
c. João engordou mais neste mês do que no ano passado todo.

(SOUZA, 2010: 7)

Seguindo a proposta de Kennedy (2007) e a tendência geral dos trabalhos interessados em uma pesquisa translinguística, enfocaremos, primeiramente, apenas as construções comparativas de superioridade de base adjetival em Karitiana, do tipo mais ADJETIVO do que. No entanto, não descartamos a importância de se investigar as comparativas de inferioridade, as equativas e as superlativas em pesquisas futuras.

\section{Construções Comparativas: um panorama translinguístico}

Dada a definição geral das estruturas comparativas, o objetivo desta seção é identificar modos de codificar essa noção encontrados nas línguas naturais. 0 intuito é observar primeiramente quais os mecanismos encontrados na expressão de comparativas em diferentes línguas do mundo antes de se analisar essas construções em Karitiana.

Os estudos sobre as construções comparativas, mais especificamente a investigação de diferentes sistemas de comparação em línguas distintas pode ser considerada vasto (ULTAN, 1972). Ultan (1972) cita, por exemplo, os trabalhos de Canger (1966), Raun (1960), Small (1929) e Valin (1952). Esta seção descreverá em mais detalhes os trabalhos de Ultan (1972) e Stassen (2013) por se tratar de trabalhos que reuniram uma grande variedade de 
línguas para a investigação das estruturas comparativas. É importante notar que uma dada língua pode apresentar mais de uma estratégia para codificar comparação. No entanto, cada língua possui uma construção mais natural ou menos marcada. Stassen (1985) classifica essas construções de comparativas primárias e estas que vão interessar para a investigação tipológica.

Ultan (1972) reuniu dados de estruturas comparativas e correlatas em 123 línguas. Segundo o autor, todas as línguas estudadas possuem alguma forma de expressar comparativas, superlativas e equativas. No entanto, nem todas as línguas possuem uma estrutura linguística especializada para expressar essas construções como mais/menos...(do) que, a mais/menos e tão...quanto em português. Dentre essas línguas, há línguas que não possuem forma especializada para indicar o índice de comparação (como o mais do português) e línguas que não possuem uma expressão para a marca do padrão de comparação (como o (do) que do português), além das línguas que não possuem nenhuma das duas formas.

O modo mais utilizado pelas línguas para expressar sentenças comparativas é por meio de um índice de comparação, como o sufixo \{-er\} do inglês ou um advérbio do tipo mais do português. No entanto, nem todas as línguas do mundo expressam comparação dessa maneira.

A segunda forma mais utilizada para se expressar comparativas é por meio de uma construção com um verbo do tipo exceder. Essas construções normalmente empregam dois predicados: o predicado comparativo e um verbo do tipo exceder cujo sujeito é o termo comparado e o objeto é o padrão de comparação (STASSEN, 2013). Das 167 línguas da amostra de Stassen (2013), 33 possuem comparativas primárias desse tipo. Segundo o autor, essas estruturas aparecem quase que exclusivamente na África Subsaariana, China e Sudeste Asiático.

O exemplo abaixo da língua luganda (nigero-congolesa, Uganda) ilustra construções desse tipo ${ }^{4}$.

$$
\begin{aligned}
& \text { Kizito a-singa Kato o-bu-kulu. } \\
& \text { Kisito Nc1-excede Kato AUG-Nc14-velho }{ }^{5} \\
& \text { 'Kisito é mais velho do que Kato.' } \\
& \text { Lit.: 'Kizito excede Kato em velhice.' }
\end{aligned}
$$

LUGANDA

(BOCHNAK, 2013: 79)

Depois de línguas que possuem uma construção especializada como o mais do português e das línguas que apresentam comparação por meio de um verbo do tipo exceder, o tipo mais comum de comparativa é por meio de uma marca zero para o índice de comparação com marca opcional do padrão de comparação. Das 123 línguas da amostra de Ultan (1972), 35 não apresentaram marca para o índice de comparação. Dentre essas línguas

\footnotetext{
${ }^{4}$ Os exemplos de outras línguas virão acompanhados de sua fonte e com as glosas fornecidas pelo autor descritas em nota de rodapé.

${ }^{5}$ Abreviações do exemplo: NC1 = classe nominal 1; AUG = aumento; NC14 = classe nominal 14.
} 
está o javanês (austronésia, Indonésia). O exemplo (6) mostra que, nessa língua, não há marcas para o índice de comparação, mas há uma marca do padrão de comparação karo que tem a mesma função do do que do português:
Enak dagingkaro
iwak.
é.bom carne do.que
peixe $^{6}$
'Carne é melhor do que peixe.'

JAVANÊS

(KENNEDY, 2007: 142)

Quase metade das línguas da amostra de Ultan (1972) empregam marcadores do padrão de comparação com uma palavra que denota separação, remoção ou destacamento. Um exemplo desse tipo de língua é o japonês (japônica, Japão) que emprega a forma yori que pode ser traduzido por 'de'.

$\begin{array}{llllll}\text { (7) Nihongo } & \text { wa } & \text { doitsgo } & \text { yori } & \text { muzukashi } & \text { JAPONÊS } \\ & \text { japonês } & \text { TOP } & \text { alemão } & \text { de } & \text { difícil }^{7}\end{array}$

'Japonês é mais difícil do que alemão.' (STASSEN, 1985: 39)

Um outro exemplo é o próprio português, que possui uma preposição de na marca do padrão de comparação. A semântica de separação e destacamento desses marcadores enfatiza a diferença entre o termo comparado e o padrão de comparação. Por conta disso, em línguas com marcação de caso, o padrão de comparação é marcado tipicamente com caso ablativo (ULTAN, 1972). A terminologia ablativo é derivada do particípio ablatum do verbo auferre que significa 'levar', 'furtar' (WELTE, 1987). Em latim (indo-europeia, língua morta) ${ }^{8}$, por exemplo, uma das formas de se expressar comparativas é de forma sintética, por meio da marca de caso ablativo do padrão de comparação.

$$
\begin{aligned}
& \text { Sole clarior. } \\
& \text { sol.ABL claro.COMPR }{ }^{9} \\
& \text { 'mais claro do que o sol' }
\end{aligned}
$$

LATIM

Além das línguas com marcas de separação do tipo da preposição de, há ainda línguas que empregam marcas com semântica de para, sobre, em direção a. Stassen (2013) classifica essas construções com marcas preposicionais com semântica posicional de comparativas locativas. Na amostra de 167 línguas utilizada pelo autor, 78 possuem comparati-

\footnotetext{
${ }^{6}$ Uma vez que o exemplo foi dado em inglês, não é possível saber exatamente qual a natureza de karo em javanês. Ela foi traduzida para than, mas não está claro se tem as mesmas propriedades que a marca do inglês.

${ }^{7}$ Glosa do exemplo: TOP = marcador de tópico.

${ }^{8}$ O latim ainda é usado em contexto litúrgico e documentos oficiais no Estado do Vaticano. De toda forma, seu estatuto é restrito a segunda língua, o que o classifica como língua morta, segundo a definição de que uma língua viva é aquela que tem falantes nativos.

${ }^{9}$ Abreviações do exemplo: $\mathrm{ABL}=$ caso ablativo; $\operatorname{COMPR}=$ comparativo.
} 
vas locativas. A sentença (9) ilustra um exemplo em taureg (afro-asiática, Argélia) que usa a preposição foull 'sobre'.

(9)
Kemmou tehousid
foull oult ma
m.
TAUREG
você ser.bonito.2sG.F sobre irmã de você ${ }^{10}$
'Você é mais bonita do que sua irmã.'
Lit.: 'Você é bonita sobre sua irmã.'
(HANOTEAU, 1896: 52)

Há outras línguas, ainda, que possuem partículas que acompanham o padrão de comparação, mas que não desempenham uma função locativa, como as apresentadas acima. O than do inglês e o que do francês são exemplos de partículas desse tipo. Na classificação de Stassen (2013), essas são as línguas com comparativas com partículas e elas representam menos de $15 \%$ da amostra de línguas analisada pelo autor.

(10) Tu es plus fort que Jean.
você é mais forte que Jean

FRANCÊS

'Você é mais forte do que o Jean.'

(ULTAN, 1972: 136, adaptado)

Ultan (1972) também destaca que as marcas para o padrão de comparação utilizadas pelas línguas frequentemente veiculam um significado que enfatiza sua diferença com o termo comparado. Segundo o autor, depois de línguas que possuem marcas de separação do tipo da preposição de, a segunda forma mais encontrada é a marca negativa. Um exemplo é o lituano (indo-europeia, Lituânia) que usa a forma nei 'nem'.

jie yra labiau energingi nei gabus.
eles são mais enérgico nem talentoso
'Eles são mais enérgicos do que talentosos.'
Lit. 'Eles são mais enérgicos nem talentosos'.

(ULTAN, 1972: 131)

Um outro tipo de marca do padrão de comparação é por meio de um pronome interrogativo como nas comparativas analíticas do latim. Quam é o pronome interrogativo no acusativo singular feminino.

clarior quam sol
claro.COMPR que sol. NOM $^{11}$
'mais claro do que o sol'

LATIM

(LEDGEWAY, 2012: 23)

Os exemplos acima mostraram exemplos de diferentes formas de se marcar o índice

\footnotetext{
${ }^{10}$ Abreviações do exemplo: $2 \mathrm{SG}=$ segunda pessoa do singular; $\mathrm{F}=$ feminino.

${ }^{11}$ Abreviações do exemplo: cOMPR = comparativo; NOM = caso nominativo.
} 
e o padrão de comparação em construções comparativas nas línguas. Mas há ainda línguas que não possuem marcas para nenhum desses elementos e expressam comparações por meio de um expediente sintático. São as línguas como o amele (trans-nova guiné, PapuaNova Guiné) que apresenta duas sentenças estruturalmente independentes para expressar comparações, uma contendo o termo comparado e outra com o padrão de comparação., conforme ilustrado em (13).

\begin{tabular}{|c|c|c|c|c|c|}
\hline \multirow[t]{2}{*}{ Jo } & i & bem & Jo & eu & \multirow{2}{*}{$\begin{array}{l}\text { nag. } \\
\text { pequena }\end{array}$} \\
\hline & esta & grande & casa & aquela & \\
\hline
\end{tabular}

(ROBERTS, 1987: 135 apud STASSEN 2013)

Stassen (2013) classifica as construções sem morfologia dedicada para comparativas como comparativas por associação (do inglês conjoined comparative). Sua amostra de línguas demonstra que essas línguas se concentram na América e na Oceania.

Esta seção mostrou as formas mais comuns de se expressar comparações nas línguas do mundo. Esse quadro ajuda a dar um panorama sobre os tipos de construções existentes antes de se analisar uma língua em específico. Esse tipo de perspectiva ajuda a neutralizar a nossa perspectiva enquanto linguistas antes de descrever fenômenos em outras línguas sem criar expectativas de construções semelhantes às do inglês, língua mais investigada na literatura linguística, e às da nossa língua nativa.

\section{Construções Comparativas em Karitiana}

\subsection{Comparativas em Karitiana: perspectiva tipológica}

O objetivo desta seção é apresentar as propriedades das construções comparativas na língua Karitiana em uma perspectiva tipológica. Karitiana é a única língua sobrevivente da família Arikém, uma das dez famílias do tronco Tupi. É falada por aproximadamente 370 pessoas de um grupo indígena de mesmo nome em uma reserva localizada a aproximadamente 90 quilômetros ao sul de Porto Velho, Rondônia ${ }^{12}$.

Em Karitiana, há mais de uma construção especializada em expressar comparação. Isso está de acordo com o que discutimos na última seção acerca das possibilidades apresentadas pelas línguas. No entanto, este artigo enfoca apenas uma de suas construções, as que nas investigações iniciais aparecerem como as mais naturais. Analisar as outras estratégias de expressão de comparação faz parte de um trabalho futuro.

Assim como em inglês e em português, em Karitiana há também uma estrutura es-

12 O dado é de 2017 do Relatório ainda não publicado sobre o Inventário Sociolinguístico da Língua Karitiana realizado pelo IPHAN e pelo MPEG: Inventário Nacional da Diversidade Linguística: Belém. 
pecializada para se fazer comparações. A palavra ohynym tem um comportamento semeIhante ao mais do português, mas significa 'maior'. A sentença (14) apresenta uma sentença comparativa em que a propriedade comparada é o tamanho. Nesse caso, ohynym faz tanto a função do elemento especializado na comparação quanto do adjetivo comparado. Ou seja, ela amalgama as noções de mais e grande (como o maior do português) ${ }^{13}$.

$\begin{array}{lrlll}\text { Luciana } & \text { ombi } & \varnothing \text {-na-aka-t } & \text { Sarita } & \text { ombi ohynym i-aka-t }{ }^{14} . \\ \text { Luciana } & \text { cesto } & 3-D E C L-C O P-N F U T & \text { Sarita } & \text { cesto maior } \\ \text { PART-COP-NFUT } & 16 \\ \text { 'O cesto da Luciana é/está maior do que o cesto da Sarita.' }\end{array}$

Já nas sentenças (15) e (16), as propriedades comparadas são pesado e bom. Nesse caso, ohynym tem apenas o papel de índice de comparação, tendo um comportamento semelhante ao do mais do português.

$\begin{array}{lrlrll}\text { Luciana } & \text { ombi } & \varnothing \text {-na-aka-t } & \text { Sarita } & \text { ombi pyti ohynym i-aka-t. } \\ \text { Luciana } & \text { cesto } & 3-D E C L-C O P-N F U T & \text { Sarita } & \text { cesto pesado maior } & \text { PART-COP-NFUT } \\ \text { 'O cesto da Luciana é/está mais pesado do que o cesto da Sarita.' } & \end{array}$

Luciana ti'y $\varnothing$-na-aka-t Karin ti'y se'a ohynym i-aka-t. Luciana comida 3-DECL-COP-NFUT Karin comida bom maior PART-COP-NFUT 'A comida da Luciana é melhor do que a comida da Karin.'

No levantamento tipológico de Ultan (1972), apenas uma língua, o coreano, apresenta como índice de comparação uma marca que carrega a noção de tamanho. No entanto, trata-se de uma marca para as comparativas equativas, conforme ilustrado abaixo.

$\begin{array}{lll}\text { San } & \text { man } & \text { nophin. } \\ \text { montanha } & \text { tamanho é-alto }\end{array}$

'Isto é tão alto quanto a montanha.'

(ULTAN, 1972: 122)

No exemplo acima, nota-se, entretanto, que a propriedade denotada pelo adjetivo que está sendo avaliada na comparativa tem uma dimensão de tamanho e isso poderia estar determinando a seleção de um índice de grau que tenha essa semântica. Ultan

\footnotetext{
${ }^{13}$ Não foi detectado de qual adjetivo a palavra ohynyn pode ter sido derivada. Em Karitiana, a palavra para 'grande' é tyt.

${ }^{14}$ Os dados da língua Karitiana presentes neste artigo foram coletados por mim por meio de elicitação controlada com falantes nativos. Seguimos a metodologia descrita em Matthewson (2004) e Autor.

${ }^{15}$ Abreviações dos exemplos do Karitiana: $\mathrm{ABS}$ = concordância absolutiva; $\mathrm{COP}$ = cópula; $\mathrm{DECL}=$ modo declarativo; NFUT = tempo não futuro; $\mathrm{OBL}=$ oblíquo; 3 = concordância de terceira pessoa; $\mathrm{PART}$ = particípio; $\mathrm{QU}$ = palavra-qu.

${ }^{16}$ Já estamos glosando os morfemas da sentença comparativa de acordo com a análise que vamos propor na seção 3.2 .
} 
(1972) não discute essa questão e também não apresenta mais exemplos desse tipo com adjetivos de natureza diferente.

Curiosamente, uma língua que tem proximidade com a marca do Karitiana e que não apareceu nas amostras tipológicas é o inglês antigo. Em inglês, a marca more tem origem na palavra ma que queria dizer 'maior' em inglês antigo (ma gode [inglês antigo] ('maior bom') = more good [inglês moderno] = 'melhor' (lit. 'mais bom') (GONZÁLEZ-DIAS, 2008). Além disso, o próprio português tem uma marca que deriva de uma palavra latina com noção de tamanho: magnum ('grande') > magis ('mais') > mais (CÂMARA JR., 1979).

Do ponto de vista tipológico, Karitiana é uma língua que apresenta uma palavra especializada para o índice de comparação que expressa a noção de tamanho, mas não possui nenhuma marca para destacar o padrão de comparação.

\subsection{Comparativas em Karitiana: uma ou duas sentenças?}

Uma outra questão que chama a atenção nos dados das construções comparativas em Karitiana está no fato de que elas parecem possuir duas sentenças, cada uma com um verbo de cópula. Retomemos o exemplo acima, repetido abaixo.

Luciana ombi $\varnothing$-na-aka-t Sarita ombi pyti ohynym i-aka-t.

Luciana cesto 3-DECL-COP-NFUT Sarita cesto pesado maior PART-COP-NFUT 'O cesto da Luciana é/está mais pesado do que o cesto da Sarita.'

No exemplo acima, aparecem dois verbos de cópula naakat e iakat, o que poderia sugerir que a estrutura literal da sentença fosse algo do tipo 'O cesto da Luciana é/está mais pesado do que o cesto da Sarita é/está'. Nesse caso, estaríamos diante de duas orações, cada uma com um verbo. Vamos explorar, primeiramente, essa hipótese, averiguando o estatuto das orações.

[O cesto da Luciana é/está mais pesado] [do que o cesto da Sarita (é/está).]

Em português, por exemplo, não há consenso a respeito da análise para as orações comparativas. Matos e Brito (2008), por exemplo, defendem que as orações comparativas são coordenadas em português. Marques (2003), por outro lado, propõe que as comparativas do português são subordinadas relativas. Já Souza (2010) defende que as sentenças comparativas são adverbiais.

Para o Karitiana, vamos explorar três hipóteses: uma de que as estruturas comparativas têm apenas uma oração e duas hipóteses de que são estruturas bi-oracionais, sendo uma que considere a comparativa como adverbial, e uma que a considere como um complemento do verbo de cópula. Vamos começar considerando as hipóteses de que essas estruturas possuem duas orações. Nesse caso, teríamos uma sentença principal com verbo tipicamente ocupando a segunda posição da sentença e uma sentença encaixada com o 
verbo ocupando a posição final.

No entanto, a divisão das duas sentenças em Karitiana é diferente da do português por conta da ordem de palavras. Em Karitiana, a propriedade pyti 'pesado' e seu índice de comparação ohynym 'maior' aparecem depois do padrão de comparação Sarita ombi 'cesto da Sarita'. Apresentamos duas possibilidades de separação entre as sentenças, uma que considera que a sentença encaixada inclui não só o padrão de comparação (como em português), mas também a propriedade comparada (20c'), uma que considera que a sentença encaixada inclui a propriedade comparada, mas não o padrão de comparação (20c'”).

(20) a. [O cesto da Luciana é/está mais pesado] [do que o cesto da Sarita (é/está)]

b. Luciana ombi naakat Sarita ombi pyti ohynym iakat.

Luciana cesto cópULA Sarita cesto pesado maior cópULA

c'. [Luciana ombi naakat] [Sarita ombi pyti ohynym iakat].

$c^{\prime \prime}$. [Luciana ombi naakat Sarita ombi] [pyti ohynym iakat].

Em $\left(20 c^{\prime}\right)$, a sentença encaixada parece se comportar como uma sentença complemento da cópula naakat. Em (20c"), a sentença comparativa tem um estatuto adverbial. As divisões em (20c') e (20c') estão de acordo com o comportamento da língua no que diz respeito à ordem de palavras. Nas sentenças matrizes, o verbo nunca aparece na posição final (SVO, OVS, VSO e VOS). A língua apresenta um movimento do verbo associado à morfologia flexional (STORTO, 1999). Nesse caso, naakat é a cópula flexionada que aparece na segunda posição depois do sintagma Luciana ombi (cesto da Luciana). O verbo flexionado apresenta morfologia de tempo, modo e pessoa (STORTO, 1999) ${ }^{17}$.

A segunda sentença da construção apresentaria o verbo na posição final. Em geral, as línguas Tupi apresentam sentenças subordinadas com o verbo não finito na posição final (GIJN, GALUCIO e NOGUEIRA, 2015). Há muitas análises dessas sentenças como nominalizações nas línguas Tupi, no entanto, Storto 2012 analisa sentenças encaixadas (adverbiais, argumentais e relativas) como versões truncadas das sentenças matrizes e não como nominalizações. Embora as sentenças encaixadas em Karitiana não apresentem morfologia de tempo, modo e concordância, elas possuem marca de aspecto que, no entanto, não são afixos do verbo, mas formam uma unidade prosódica e sintática independente (STORTO, 2012), conforme ilustrado abaixo.

\begin{tabular}{|c|c|c|c|c|}
\hline $\begin{array}{l}\text { [Ti'y } \\
\text { comida }\end{array}$ & $\begin{array}{l}\text { Marcelo } \\
\text { Marcelo }\end{array}$ & $\begin{array}{ll}\text { ‘y } & \text { tykiri] } \\
\text { comer } & \text { PERF }\end{array}$ & $\begin{array}{l}\varnothing \text {-na-pa'ira-t } \\
\text { 3-DECL-raiva-NFUT }\end{array}$ & $\begin{array}{l}\text { João. } \\
\text { João }\end{array}$ \\
\hline
\end{tabular}

\footnotetext{
${ }^{17}$ Alternativamente, Landin (1984) e Everett (2006) não consideram a marca de pessoa no verbo como flexão de concordância, mas como pronomes. Para os propósitos deste artigo, não é preciso escolher entre uma das duas análises.
} 
Voltando, para as sentenças comparativas, na hipótese em que apresentam uma sentença adverbial, sentenças com o sufixo $\{-t\}$ do verbo $i$ - $a k a-t$ poderia ser analisado como adverbializador.

[Luciana ombi $\varnothing$-na-aka-t Sarita ombi] [pyti ohynym i-aka-t.] Luciana cesto 3-DECL-COP-NFUT Sarita cesto pesado maior PART-COP-NFUT 'O cesto da Luciana é/está mais pesado do que o cesto da Sarita.'

$O$ adverbializador $\{-t\}$ é um sufixo comum em advérbios e sentenças adverbiais em Karitiana, conforme ilustram os exemplos abaixo.
a. João i-otam- $\varnothing$
koo-t.
João PART-chegar-ABS
ontem-ADV
'O João chegou ontem.'
b. João $\varnothing$-naka-tagngã-t gooj soaso-t.
João 3-DECL-dirigir-NFUT carro rápido-ADV
'O João dirige rápido o carro.'
c. João i-otam- $\varnothing$ kama-t.
João PART-chegar-ABS agora-ADV
'O João chegou agora.'

(SANCHEZ-MENDES, 2014: 178)
(24) [Gok eT(Donso amang-ã tyki'oo-t] $\varnothing$-na-oky-t him taso.
[macaxeira mulher plantar-VT IMP-ADV] 3-DECL-matar-NFUT caça homem
'Enquanto a mulher estava plantando macaxeira, o homem matou a caça.'

(ROCHA, 2013: 6)

Para a consideração de que as sentenças comparativas envolvem sentenças adverbiais, seria preciso, ainda oferecer uma análise para o prefixo $\{i-\}$ de $i$-aka-t. Não vamos explorar uma proposta desse tipo.

Consideremos, alternativamente, a hipótese de que se trata de uma sentença complemento do verbo de cópula. Nesse caso, a construção comparativa parece apresentar uma construção de cópula específica, uma estrutura linguística bastante recorrente em Karitiana que pode ocorrer tanto com substantivos e adjetivos quanto com verbos intransitivos (STORTO, 2010). As sentenças abaixo ilustram essa construção com predicado nominal kinda'o 'fruta' e com o adjetivo se'a 'bom'.

a.

Byyty

mamão

$\varnothing$-na-aka-t

kinda'o-t.

'Mamão é fruta.' 


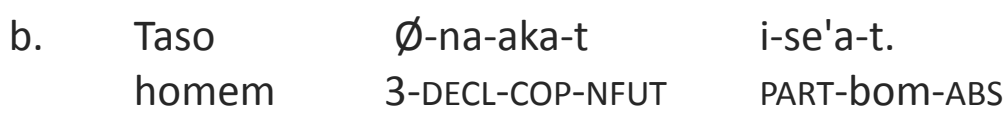

'O homem é bom.'

(STORTO 2010: 2)

Uma diferença que se nota da comparação das duas sentenças acima é que um prefixo $\{i$ - $\}$ aparece com o adjetivo. $O$ mesmo prefixo aparece quando a cópula ocorre com um verbo intransitivo, como kat 'dormir'.

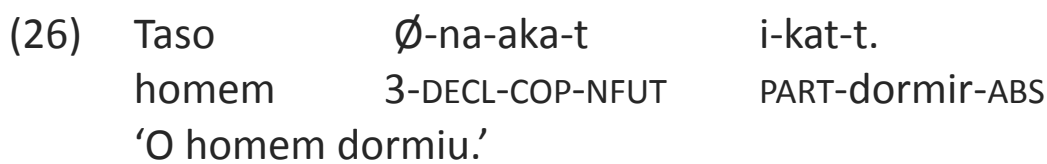

(STORTO, 2010: 2)

Storto (2010) analisa as sentenças copulares em Karitiana como sentenças bioracionais. A predicação copular naakat pode aparecer com substantivos, adjetivos ou verbos intransitivos. O verbo de cópula seleciona uma minioração nominalizada como complemento, por isso a presença do prefixo $\{i$ - $\}$ de particípio quando o complemento é um verbo ou adjetivo. Essas sentenças são entendidas como sentenças de alçamento do sujeito da minioração para a posição pré-copular, uma posição de foco. O sufixo $\{-t\}$ que aparece na minioração é uma marca morfossintática desse movimento do sujeito ${ }^{18}$. Por isso, ele foi glosado como concordância absolutiva por Storto (2010). Sintaticamente, a estrutura da cópula é a seguinte:

Sujeito ${ }_{i}$ naakat $\left[\right.$ nom $\left._{\text {Mo }} t_{i} X\right]$ ]

Em que $X$ pode ser um substantivo, um adjetivo ou um verbo intransitivo.

Vemos, portanto, que, em Karitiana, a predicação com adjetivo tem uma construção específica que apresenta um prefixo $\{i-\}$ de particípio e um sufixo $\{-t\}$ de absolutivo. Essas marcas não aparecem, no entanto, nas sentenças comparativas. Compare, por exemplo, as sentenças abaixo, uma com a predicação adjetival e outra com a comparativa. (28a) apresenta o adjetivo pyti 'pesado' com os morfemas da construção de cópula típica, enquanto que em (28b) o adjetivo aparece sem nenhuma marca.
a. Luciana
ombi $\varnothing$-na-aka-t
i-pyti-t.
Luciana
cesto 3-DECL-COP-NFUT
PART-pesado-ABS
'O cesto da Luciana está pesado.'
b. Luciana ombi $\varnothing$-na-aka-t Sarita ombi pyti ohynym i-aka-t.
Luciana cesto 3-DECL-COP-NFUT Sarita cesto pesado maior PART-COP-NFUT 'O cesto da Luciana está mais pesado do que o cesto da Sarita.'

\footnotetext{
${ }^{18}$ A marca é $\{-t\}$ se o adjetivo ou o verbo terminam com vogal. Quando terminam com consoante, o sufixo é $\{-\varnothing\}$.
} 
Esses dados indicam que, em (27b), o complemento da cópula naakat não poderia ser o adjetivo, mas poderia ser o outro verbo de cópula que aparece no final da sentença com a morfologia típica de um complemento de cópula (compare, por exemplo com o verbo ikat do exemplo (26)). Dessa forma, a comparativa parece apresentar um verbo de cópula flexionado na construção especial com naakat. Isso quer dizer que, além de substantivos, adjetivos e verbos intransitivos, verbos copulares também poderiam aparecer como complementos de cópula em Karitiana. Isso estaria de acordo com a afirmação em Rocha (2011) de que o verbo aka tem a mesma distribuição dos verbos intransitivos em Karitiana.

Embora essa análise pareça estar indo pelo caminho certo, de acordo com a morfologia apresentada pelos verbos copulares, gostaríamos de explorar uma terceira via de análise: a de que, na realidade, as construções comparativas são formadas por uma oração apenas com um verbo auxiliar conjugado e um verbo principal no particípio. Uma proposta nesse sentido parece mais adequada porque é mais econômico considerar que o verbo no particípio é simplesmente um elemento da perífrase verbal (auxiliar+verbo principal) e não um verbo nominalizado complemento de uma minioração.

A análise da perífrase verbal está de acordo com a proposta de que, do ponto de vista sintático, a língua Karitiana apresenta um efeito V-2 semelhante ao encontrado em alemão (STORTO, 1999). Em alemão, o verbo auxiliar aparece na segunda posição da sentença e o verbo participial aparece na posição final. Observe a semelhança das construções comparativas em Karitiana com a sentença declarativa do alemão apresentada abaixo.

Das Buch hat mein Freund dem Mann gestern
o.acc livro tem meu amigo o.dat homem ontem
'Meu amigo deu o livro para o homem ontem.'
(SANTORINI, KROCH, 2007)

Dadas as propriedades discutidas acima, defendemos neste artigo que as sentenças comparativas apresentam apenas um verbo de cópula que aparece com um verbo de cópula como auxiliar na construção. Elas são, portanto, formadas por apenas uma oração. Apresentamos abaixo nossa proposta:

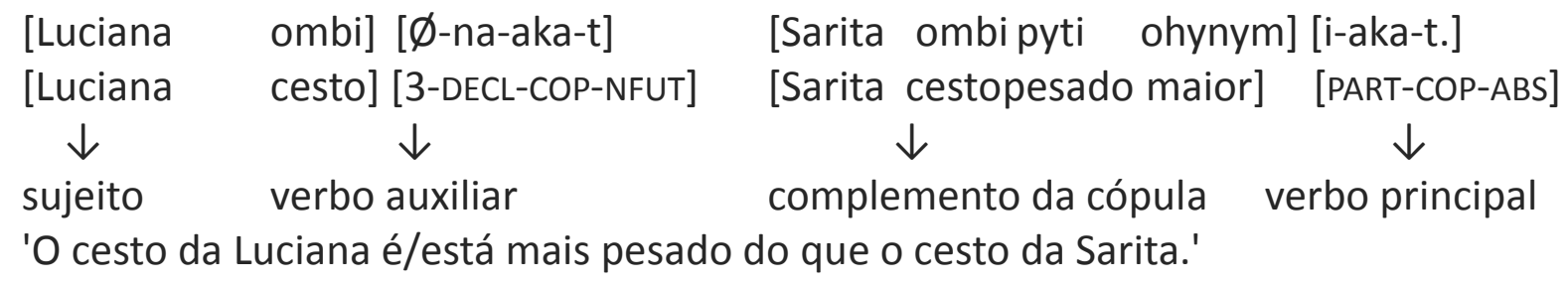

Para concluir a proposta, é preciso oferecer uma análise do sufixo $\{-t\}$ de $i$-aka-t. Esse é um sufixo que tem muitos homófonos. Como vimos, ele pode ser marca de não futuro, de adverbializador, de concordância absolutiva. Esse sufixo poderia marcar concordância com o absolutivo, em consonância com a análise de Storto (2010) para as construções de cópula. No entanto, no caso dos verbos no particípio, propomos que se trata de uma 
marca de tempo não futuro (indicando particípio não futuro). Como se sabe, há línguas que marcam tempo no particípio, como o latim clássico, que possuía uma particípio passado, um presente e um futuro.

\section{Considerações Finais}

Este artigo apresentou uma descrição preliminar das construções comparativas em Karitiana. Em uma perspectiva tipológica, as comparativas podem assumir estruturas bastante diferentes, no entanto, vimos que todas a as línguas possuem algum mecanismo especializado para expressar comparações. Em Karitiana, o mecanismo básico investigado foi o de sentenças com o índice de comparação okynym que, quando aparece sozinho, expressa a noção de maior, mas quando está acompanhado de outros adjetivos, faz o papel de índice de comparação, como o mais do português.

Do pondo de vista morfossintático, analisamos ainda se as construções comparativas apresentam uma ou duas sentenças. Depois de explorar cada uma das hipóteses, propusemos que se trata de apenas uma oração com dois verbos de cópula: um auxiliar e um principal. Propomos especulativamente que essa análise pode ser adequada também para todos os casos em que há um verbo na construção de cópula. Storto (2010) analisa esses casos como contendo uma minioração com um verbo nominalizado na posição de complemento de cópula. É mais econômico supor, no entanto, que esse é um caso de perífrase verbal em que aparece uma cópula conjugada e um verbo no particípio. Na avaliação de duas propostas igualmente adequadas empiricamente, deve-se optar por aquela que é mais simples. Esse princípio é conhecido na Filosofia da Ciência como Lei da Parcimônia ou Navalha de Occam.

Há ainda algumas questões que ficam para pesquisa futura, tais como: (i) haveria em Karitiana outras formas de se expressar comparativas de superioridade?; (ii) como a língua expressaria comparativas equativas e de inferioridade; e as superlativas?

\section{Referências}

BOCHNACK, M. R. Cross-linguistic variation in the semantics of comparatives. Tese de Doutorado. Univesity of Chicago, 2013.

CÂMARA JR.; MATTOSO. História e Estrutura da Língua Portuguesa. Rio de Janeiro: Padrão, 1979.

CANGER, U. The category of comparison. Bulletin de la Societé Polonaise de Linguistique 24, p. 145-161, 1966.

DIXON, R. M. W. Comparative constructions: a cross-linguistic typology. Studies in Language, 32 (4), p. 787-817, 2008.

EVERETT, C. Patterns in Karitiana: Articulation, perception, and grammar. 2006. Tese de Doutorado. Rice University, EUA.

FRANK, M. C.; EVERETT, D.; FEDORENKO, E.; GIBSON, E. Number as a cognitive technology: 
Evidence from Piraha language and cognition. Cognition 108, p. 819-824, 2008.

GIJN, R. V.; GALUCIO, A. V. NOGUEIRA, A. F. Subordination strategies in Tupian languages. Boletim do Museu Paraense Emílio Goeldi. Ciências Humanas 10(2), p. 297-324, 2015. GONZÁLEZ-DIAZ, V. English adjective comparison: a historical perspective. Amsterdam: John Benjamins, 2008.

HANOTEAU, A. Essai de grammaire de la langue tamachek'. Algiers: Jourdan, 1896.

KENNEDY, C. Modes of comparison. In: ELLIOT, M.; KIRBY, J.; SAWADA, O. STARAKI, E.; YOON, S. (eds.) Proceedings from the Annual Meeting of the Chicago Linguistic Society 43, n. 1, Chicago: Chicago Linguistic Society, 2007. p. 141-165.

LANDIN, D. An Outline of the Syntactic Structure of Karitiana Sentences. Estudos Sobre Línguas Tupi do Brasil. Série Linguística 11. Brasília: SIL, 1984.

LEDGEWAY, A. From Latin to Romance: morphosyntactic typology and change. Oxford: Oxford University Press, 2012.

MARQUES, R. R. Para uma semântica das construções comparativas em português. Tese de Doutorado. Universidade de Lisboa, 2003.

MATOS, G.; BRITO, A. Comparative clauses and cross-linguistic variation: a syntactic approach. In: BONANI, O.; HOFHERR, P. C. (orgs.). EISS 7, 2008. p. 307-329.

MATTHEWSON, L. On the Methodology of Semantic Fieldwork. International Journal of American Linguistics 70, p. 369-415, 2004.

RAUN, A. The equivalents of English "than" in Finno-Ugric. American Studies in Uralic Linguistics. 1960.

ROCHA, I. A estrutura Argumental da Língua Karitiana: Desafios Descritivos e Teóricos. 2011. Dissertação (Mestrado em Semiótica e Linguística Geral) - Faculdade de Filosofia, Letras e Ciências Humanas, Universidade de São Paulo, São Paulo.

- Valência Verbal e núcleos aspectuais em orações subordinadas em Karitiana:

o caso das relativas e adverbiais. Trabalho apresentado no II Workshop de Línguas Indígenas da USP. 2013.

SAPIR, E. Grading: a study in semantics. Philosophy of Science 11, p. 93-116. 1944.

SANTORINI, B.; KROCH, A. The syntax of natural language: An online introduction using the Trees program. 2007. Disponível em: <http://www.ling.upenn.edu/ beatrice/syntaxtextbook.>. Acesso em 17 mai. 2017.

SMALL, G. W. The Germanic case of comparison, with a special study of English. Philadelphia: Linguistic Society of America, 1929.

SOUZA, L. Comparativas Quantificacionais no Português Brasileiro: Semântica e Sintaxe. Tese de Doutorado. Universidade Federal de Santa Catarina, 2010.

STASSEN, L. Comparison and Universal Grammar. Oxford: Basil Blackwell: 1985.

. Comparative Constructions. In: DRYER, M. S.; HASPELMATH, M. (eds.) The World Atlas of Language Structures Online. Leipzig: Max Planck Institute for Evolutionary Anthropology, 2013. Disponível em http://wals.info/chapter/121. Acesso em 8 mai. 2015. von STECHOW, A. Comparing Semantic Theories of Comparison. Journal of Semantics 3, $p$. 1-77, 1984. 
STORTO, L. Aspects of Karitiana Grammar. 1999. Tese (Doutorado em Linguística) - MIT, EUA.

. Copular Constructions in Karitiana: a case against case movement. In: LIMA.

S. (ed.) University of Massachusetts Occasional Papers 41: Proceedings of SULA 5: Semantics of Under-Represented Languages in the Americas. Amherst: GLSA/The University of Massachusetts, 2010.

- Subordination in Karitiana. Amerindia (Revue d'Ethnolinguistique

Amérindienne 35, p. 219-237, 2012.

ULTAN, R. Some features of basic comparative constructions. Working Papers on Language Universals, No. 9, p. 117-162, 1972.

VALIN, R. Esquise d'une théorie des degrés de comparaison. Cahiers de Linguistique Structurale 2, 1952.

WELTE, W. On the Concept of Case in Traditional Grammars. In: DIRVEN, R.; GÜNTER, R. (eds.) Concepts of Case. Tübingen: Narr, 1987. p. 15-27. 